\title{
Low cigarette consumption and risk of coronary heart disease and stroke: meta-analysis of 141 cohort studies in 55 study reports
}

\author{
Allan Hackshaw, ${ }^{1}$ Joan K Morris, ${ }^{2}$ Sadie Boniface, ${ }^{3}$ Jin-Ling Tang, ${ }^{4}$ Dušan Milenkovic ${ }^{5}$
}

${ }^{1}$ Cancer Research UK and UCL

Cancer Trials Centre, University

College London, London W1T

4TJ, UK

${ }^{2}$ Wolfson Institute of

Preventive Medicine, Queen

Mary, University of London,

London, UK

${ }^{3}$ Addictions Department, Kings

College London, London, UK

${ }^{4}$ IC School of Public Health and

Primary Care, Chinese University

of Hong Kong, Hong Kong

${ }^{5}$ Meta Research, Evidera,

London, UK (formerly Cancer

Research UK and UCL Cancer

Trials Centre)

Correspondence to:

A Hackshaw

a.hackshaw@ucl.ac.uk

Additional material is published online only. To view please visit

the journal online.

Cite this as: $B M J$ 2018;360:j5855 http://dx.doi.org/10.1136/bmj.j5855

Accepted: 11 December 2017

\section{ABSTRACT}

OBJECTIVE

To use the relation between cigarette consumption and cardiovascular disease to quantify the risk of coronary heart disease and stroke for light smoking (one to five cigarettes/day).

\section{DESIGN}

Systematic review and meta-analysis.

\section{DATA SOURCES}

Medline 1946 to May 2015, with manual searches of references.

\section{ELIGIBILITY CRITERIA FOR SELECTING STUDIES}

Prospective cohort studies with at least 50 events, reporting hazard ratios or relative risks (both hereafter referred to as relative risk) compared with never smokers or age specific incidence in relation to risk of coronary heart disease or stroke.

\section{DATA EXTRACTION/SYNTHESIS}

MOOSE guidelines were followed. For each study, the relative risk was estimated for smoking one, five, or 20 cigarettes per day by using regression modelling between risk and cigarette consumption. Relative risks were adjusted for at least age and often additional confounders. The main measure was the excess relative risk for smoking one cigarette per day $\left(R_{1}\right.$ _per_day -1$)$ expressed as a proportion of that for smoking 20 cigarettes per day $\left(R_{20 \_p e r d a y}-1\right)$, expected to be about $5 \%$ assuming a linear relation between risk and consumption (as seen with lung cancer). The relative risks for one, five, and 20 cigarettes per day were also pooled across all studies in a random effects meta-analysis. Separate

\section{WHAT IS ALREADY KNOWN ON THIS TOPIC}

Smoking increases the risk of developing coronary heart disease and stroke Many smokers believe that cutting down the number of cigarettes they smoke substantially reduces their risk of developing tobacco related disorders Occasional individual studies and a meta-analysis of five studies in 1997 reported that light cigarette smoking (less than five per day) is associated with a higher than expected risk of coronary heart disease

\section{WHAT THIS STUDY ADDS}

Men who smoke about one cigarette per day have a $48 \%$ higher risk of heart disease than never smokers and a $25 \%$ higher risk of stroke (or $74 \%$ and $30 \%$, respectively, when allowing for confounding factors)

The estimates are higher in women: $57 \%$ for heart disease and 31\% for stroke (or $119 \%$ and $46 \%$ when allowing for multiple confounders), again compared with never smokers.

People who smoke about one cigarette each day have about $40-50 \%$ of the excess risk associated with smoking 20 per day (coronary heart disease and stroke) analyses were done for each combination of sex and disorder.

\section{RESULTS}

The meta-analysis included 55 publications containing 141 cohort studies. Among men, the pooled relative risk for coronary heart disease was 1.48 for smoking one cigarette per day and 2.04 for 20 cigarettes per day, using all studies, but 1.74 and 2.27 among studies in which the relative risk had been adjusted for multiple confounders. Among women, the pooled relative risks were 1.57 and 2.84 for one and 20 cigarettes per day (or 2.19 and 3.95 using relative risks adjusted for multiple factors). Men who smoked one cigarette per day had $46 \%$ of the excess relative risk for smoking 20 cigarettes per day (53\% using relative risks adjusted for multiple factors), and women had $31 \%$ of the excess risk (38\% using relative risks adjusted for multiple factors). For stroke, the pooled relative risks for men were 1.25 and 1.64 for smoking one or 20 cigarettes per day (1.30 and 1.56 using relative risks adjusted for multiple factors). In women, the pooled relative risks were 1.31 and 2.16 for smoking one or 20 cigarettes per day (1.46 and 2.42 using relative risks adjusted for multiple factors). The excess risk for stroke associated with one cigarette per day (in relation to 20 cigarettes per day) was $41 \%$ for men and $34 \%$ for women (or $64 \%$ and $36 \%$ using relative risks adjusted for multiple factors). Relative risks were generally higher among women than men.

\section{CONCLUSIONS}

Smoking only about one cigarette per day carries a risk of developing coronary heart disease and stroke much greater than expected: around half that for people who smoke 20 per day. No safe level of smoking exists for cardiovascular disease. Smokers should aim to quit instead of cutting down to significantly reduce their risk of these two common major disorders.

\section{Introduction}

Around one billion adults worldwide smoke, ${ }^{1}$ with high prevalence in developing countries, where $49 \%$ of men and $11 \%$ of women use tobacco. ${ }^{2}$ Although the prevalence of current smokers has decreased over time in several countries, the global absolute number of smokers has increased owing to population growth. ${ }^{3}$ Policies have successfully encouraged people to quit, using aids such as nicotine replacement therapy and electronic cigarettes (e-cigarettes). ${ }^{4}$

In the Health Survey for England (2013 and 2014), $26 \%$ of current smokers reported that they wanted to cut consumption down but were not trying to stop, and 
$40-41 \%$ said that they smoked less than in the previous year. ${ }^{5}$ The percentage of smokers who consume one to five cigarettes per day has steadily risen (from $18.2 \%$ to $23.6 \%$ between 2009 and $2014^{5}$ ), with a similar pattern in the US, where the proportion of smokers who consume less than 10 cigarettes per day increased from $16 \%$ to $27 \%$ between 2005 and 2014 . $^{6}$ A recent Cochrane review discussed the evidence for ways of helping smokers who wish to reduce their consumption. $^{7}$

Smoking few cigarettes is generally believed to be relatively safe, as has been incorrectly assumed for light/low nicotine cigarettes. ${ }^{8}$ Among 24658 US adolescents, $10 \%$ thought that light smoking was not harmful, and only $35 \%$ of light smokers considered their habits to be associated with "a lot of harm." Reducing consumption might be expected to reduce harm in a proportionate way-that is, that smoking one instead of 20 cigarettes per day has about one twentieth (5\%) of the risk. This seems to be the case for lung cancer, for which the large American Cancer Society Prevention Study II showed an approximately linear relation between risk of lung cancer and number of cigarettes smoked per day, but the dose-response for cardiovascular disease is steep at low consumption and then levels off, ${ }^{10}$ consistent with the shape reported previously. ${ }^{11}$

In a seminal systematic review of second-hand smoke and coronary heart disease among never smokers published in the BMJ 20 years ago, Law and colleagues drew attention to the 1.30 risk ratio being relatively large compared with the 2-3 typically seen in studies of active smokers. ${ }^{12}$ Their conclusions on second-hand smoke were supported by a meta-analysis of active cigarette smoking and risk of coronary heart disease from five cohort studies, in which the modelled relative risk for smoking one cigarette per day (1.39) was consistent with that for exposure to second-hand smoke.

Although the non-linear relation between coronary heart disease and low cigarette consumption has been reported before (individual studies, as well as official reports from the US Surgeon General), it still is still not commonly known by the general public or health professionals, particularly those not involved in tobacco and health. We thus aimed to extend the previous work on coronary heart disease, ${ }^{12}$ by using a systematic review to provide a major body of evidence. We also aimed to show that a similar non-linear relation exists between stroke and low cigarette consumption.

\section{Methods}

\section{Data sources and searches}

We did a systematic literature review of English language articles published between 1946 and May 2015 in Medline (MOOSE guidelines ${ }^{13}$ ) that reported the association between cigarette consumption and coronary heart disease and stroke. Supplementary figure A shows the search terms and flowchart: 13861 abstracts were reviewed (by DM and SB), and any selected for consideration had their reference list manually checked for additional studies. Several study reports were based on combining data from at least two separately conducted cohort studies.

\section{Study selection and data extraction}

We included prospective cohorts with at least 50 cardiovascular disease events (mortality, morbidity, or both) to minimise the potential for reporting bias, in which large but unreliable effects might be seen in small studies. Reports had to give hazard ratios from a Cox proportional hazards regression or relative risks based on incidence/mortality, which must have been adjusted by at least age, or incidence reported in age groups. Results had to be available in at least three smoking categories, not including the reference group of never smokers. The populations of the cohorts had to be generally healthy; we excluded studies based only on people at high risk (for example, taking drugs for cardiac related disorders). Results had to be given separately for men and women, or, if they were based on both combined, the hazard ratios must be adjusted for age and sex. We excluded six studies spuriously showing that the hazard ratio or relative risk decreased with increasing consumption (justification in supplementary figure A). Study characteristics extracted were country, time period, sex, smoking categories, incidence, hazard ratio or relative risk, number of participants, number of events, and confounding factors adjusted for. In the few instances in which only age adjusted incidence/mortality results were available, we calculated the relative risk in each smoking category. Most studies reported hazard ratios, and we always used hazard ratios adjusted for multiple factors when provided (supplementary table A); 30 of the 55 publications made allowance for multiple (at least two) factors in addition to age and sex when providing hazard ratios. We extracted hazard ratios and relative risks separately for coronary heart disease, stroke, or cardiovascular disease (coronary heart disease and stroke combined).

\section{Statistical methods}

Hereafter, we refer to hazard ratio or relative risk as relative risk (consistent with many studies included). Instead of modelling risk with consumption for each study (which is non-linear), we modelled the logarithm of risk, using similar methods as before. ${ }^{12}$ ${ }^{14}$ This involved fitting a log-linear variance weighted regression model between incidence or relative risk and cigarette consumption (using all reported smoking categories in the publications). Although this approach makes the relation more linear (when examined on a log scale), it might still underestimate the increase in risk at very low consumption levels.

We obtained a regression model for each study report separately (Stata software). For consumption, we used the midpoint of the reported number of cigarettes per day-for example, three cigarettes per day if the category was one to five cigarettes per daywhich we then adjusted for carboxyhaemoglobin and cotinine because this allows for lower inhalation 
with increasing cigarette consumption as previously established. ${ }^{14}$ For studies that reported relative risks adjusted for age (or for additional factors), the model contained the logarithm of the relative risk (dependent variable) and consumption (independent variable) using only the midpoint of the cigarettes per day categories. For studies that reported incidence in each age category, we fitted log-linear model that contained incidence (dependent variable) and consumption (independent variable) with age as a covariate (median age in each age category), and we estimated the relative risk by using an interaction term between age and consumption. This provided estimates in each age category $(45,55$, and 65 years) because the risk of cardiovascular disease changes with age. ${ }^{15}$ The reference value of 1.0 (never smokers) was not included in the regression to avoid forcing the model through the origin and unduly affecting the doseresponse relation (also because we were ultimately interested only in comparing between high and low consumption). We used the standard error of the logarithm of the relative risk, or the number of events if the standard error was unavailable, as weights in the regression; if both were unavailable, we did an unweighted log-linear regression for the study. The reference group was lifelong never smokers, although in seven reports it was unclear whether former smokers might have been included.

The main quantitative measure was the percentage change in risk (excess relative risk) associated with smoking one (or five) cigarette(s) per day, expressed as a proportion of the percentage change for smoking 20 cigarettes per day. For example, if the relative risks were 1.4 and 1.9 for smoking one and 20 cigarettes per day, respectively, the proportion of excess relative risk associated with one cigarette per day is $44 \%$ : $(1.4-1) /(1.9-1) \times 100$. One or five cigarettes per day reflect typical levels of low consumption. We did three different types of analyses, to check for consistency. Firstly, from each regression analysis for each study, we used the model to estimate the relative risk for smoking one cigarette per day compared with never smokers, and also for smoking five and 20 cigarettes per day. We then calculated the excess relative risks for one and five cigarettes per day (compared with 20) and took the median value of each of these across studies. We did multiple separate analyses according to combinations of sex and disease type ("within study" analyses). Secondly, we obtained a single regression model across all studies (again done separately for each combination of sex and disorder) by using the individual cigarettes per day values and reported relative risk estimates (log scale) in a random effects meta-regression (SAS Proc Mixed). We then used the pooled coefficients to estimate the relative risk for one, five, and 20 cigarettes per day (another "within study" analysis). We also used these regressions to examine whether a quadratic trend might be better than a linear trend but found no evidence of this (the quadratic coefficients were negligible and not statistically significant). Thirdly, from the log-linear regression model in each study, we estimated the relative risk for smoking one cigarette per day and then combined these across studies in a random effects meta-analysis, fitted separately for each disease group and sex, using RevMan; we repeated this for smoking five and 20 cigarettes per day. These results (and corresponding diagrams) indicate the variability in relative risk in each smoking group across studies, but they do not directly reflect the within study correlation between risk and consumption (as in the first and second analyses above).

The results are examined in relation to assuming that smoking one cigarette per day is associated with about $5 \%$ of the excess relative risk when smoking 20 cigarettes per day. Our regressions used a logarithmic scale, so smoking one cigarette per day would actually have $3.5 \%$ or $5.5 \%$ of the excess risk if the relative risk for 20 cigarettes per day was 2.0 or 3.0, respectively, values typically seen in the studies (log(relative risk for 20 cigarettes per day $)=20 \times \log$ (relative risk for one cigarette per day)).

\section{Patient involvement}

No patients were involved in setting the research question or the outcome measures, nor were they involved in developing plans for design or implementation of the study. No patients were asked to advise on interpretation or writing up of results. There are no plans to disseminate the results of the research to study participants or the relevant patient community. We did not evaluated whether the studies included in the meta-analysis had any patient involvement.

\section{Results}

The meta-analyses were based on 141 separately conducted cohort studies contained in 55 study reports (several involved the pooling of multiple studies), ${ }^{16-70}$ and two other study reports are referred to later on. ${ }^{71} 72$ Table 1 shows all summary results.

\section{Coronary heart disease}

The pooled relative risk from 26 study reports was 1.48 (95\% confidence interval 1.30 to 1.69 ) for men who smoked, on average, one cigarette per day and 1.58 (1.39 to 1.80) for those who smoked five cigarettes per day; the relative risk for smoking 20 cigarettes per day was 2.04 (1.86 to 2.24) (fig 1; supplementary figure B). (Excluding three studies that might have included former smokers in the reference group increased the relative risks for one and 20 cigarettes per day to 1.53 and 2.09, as expected.) Figure 2 shows the distribution of the excess relative risks; most had values of at least $25 \%$. Using within study comparisons, smoking one cigarette per day had $46 \%$ (interquartile range 24-56\%) of the excess relative risk for that when smoking 20 cigarettes per day, and the corresponding estimate for five cigarettes per day was 57\% (36-64\%).

The 18 reports of women showed that one cigarette per day had $31 \%$ (interquartile range $2-46 \%$ ) of the excess risk of 20 cigarettes per day (pooled relative risks $1.57 v 2.84$ ), and smoking five cigarettes per 


\begin{tabular}{|c|c|c|c|c|c|c|c|c|}
\hline \multirow[b]{2}{*}{ Cohort } & \multirow{2}{*}{$\begin{array}{l}\text { No of } \\
\text { study } \\
\text { reports }\end{array}$} & \multirow{2}{*}{$\begin{array}{l}\text { Approximate } \\
\text { No of } \\
\text { participants }\end{array}$} & \multirow{2}{*}{$\begin{array}{l}\text { Approximate } \\
\text { No of events }\end{array}$} & \multicolumn{3}{|c|}{$\begin{array}{l}\text { Pooled relative risk }(95 \% \mathrm{Cl}) \text { for smoking (compared with } \\
\text { never smokers)* }\end{array}$} & \multicolumn{2}{|c|}{$\begin{array}{l}\text { Excess relative risk, as \% of that } \\
\text { for } 20 \mathrm{CPD} t\end{array}$} \\
\hline & & & & 1 CPD & 5 CPD & 20 CPD & 1 CPD & 5 CPD \\
\hline \multicolumn{9}{|c|}{ Coronary heart disease } \\
\hline Men & 26 & 2.31 million & 57152 & $\begin{array}{l}1.48(1.30 \text { to } 1.69) ; \\
(1.45) \ddagger\end{array}$ & $\begin{array}{l}1.58(1.39 \text { to } 1.80) ; \\
(1.56) \ddagger\end{array}$ & $\begin{array}{l}2.04(1.86 \text { to } 2.24) ; \\
(2.06) \ddagger\end{array}$ & 46; (46)*; (42)‡ & $57 ;(56)^{\star} ;(53) \neq$ \\
\hline Women & 18 & 2.34 million & 29870 & $\begin{array}{l}1.57(1.29 \text { to } 1.91) ; \\
(1.59) \ddagger\end{array}$ & $\begin{array}{l}1.76 \text { (1.46 to } 2.13) ; \\
(1.79) \ddagger\end{array}$ & $\begin{array}{l}2.84(2.21 \text { to } 3.64) ; \\
(2.81) \ddagger\end{array}$ & 31; (31)*; (33)‡ & 43; (41)*; (44) \\
\hline Combined & 5 & 1.01 million & 15153 & $\begin{array}{l}1.65(1.53 \text { to } 1.78) ; \\
(1.67) \neq\end{array}$ & $\begin{array}{l}1.72(1.62 \text { to } 1.83) \\
(1.81) \neq\end{array}$ & $\begin{array}{l}2.34 \text { (1.96 to } 2.79) ; \\
(2.44) \ddagger\end{array}$ & 53; (49)*; (47)‡ & $61 ;(54)^{\star} ;(56) \neq$ \\
\hline \multicolumn{9}{|l|}{ Men aged: } \\
\hline 45 years & 8 & \multirow[t]{3}{*}{938000} & \multirow[t]{3}{*}{27697} & 1.65 (1.26 to 2.16$)$ & 1.81 (1.40 to 2.33$)$ & $2.72(2.16$ to 3.43$)$ & 35 & 46 \\
\hline 55 years & 8 & & & 1.41 (1.17 to 1.70$)$ & 1.51 (1.27 to 1.80$)$ & $2.03(1.74$ to 2.36$)$ & 33 & 44 \\
\hline 65 years & 8 & & & 1.17 (0.96 to 1.43$)$ & $1.24(1.03$ to 1.48$)$ & $1.49(1.28$ to 1.74$)$ & 20 & 36 \\
\hline \multicolumn{9}{|c|}{ Women aged: } \\
\hline 45 years & 3 & \multirow[t]{3}{*}{555000} & \multirow[t]{3}{*}{14665} & 1.26 (0.98 to 1.62$)$ & $1.34(0.92$ to 1.96$)$ & 2.19 (1.11 to 4.32) & 11 & 26 \\
\hline 55 years & 3 & & & 1.21 (1.05 to 1.39$)$ & 1.26 (0.98 to 1.62$)$ & $1.77(1.00$ to 3.11$)$ & 15 & 28 \\
\hline 65 years & 3 & & & $1.15(1.06$ to 1.25$)$ & $1.24(1.11$ to 1.40$)$ & 1.47 (0.94 to 2.29$)$ & 36 & 45 \\
\hline \multicolumn{9}{|l|}{ Stroke } \\
\hline Men & 17 & 3.40 million & 71173 & $\begin{array}{l}1.25(1.13 \text { to } 1.38) \\
(1.37) \ddagger\end{array}$ & $\begin{array}{l}1.30 \text { (1.18 to } 1.43) ; \\
(1.42) \ddagger\end{array}$ & $\begin{array}{l}1.64(1.48 \text { to } 1.82) ; \\
(1.62) \ddagger\end{array}$ & 41; (39)*; (60)‡ & 52; $(47)^{\star} ;(68) \neq$ \\
\hline Women & 10 & 3.59 million & 60520 & $\begin{array}{l}1.31(1.13 \text { to } 1.52) ; \\
(1.35) \ddagger\end{array}$ & $\begin{array}{l}1.44(1.22 \text { to } 1.70) ; \\
(1.48) \neq\end{array}$ & $\begin{array}{l}2.16(1.69 \text { to } 2.75) ; \\
(2.13) \ddagger\end{array}$ & $34 ;(27)^{\star} ;(31) \neq$ & 44; (38); (42)‡ \\
\hline Combined & 2 & 228000 & 2874 & $\begin{array}{l}1.52(1.10 \text { to } 2.10) \\
(1.56) \neq\end{array}$ & $\begin{array}{l}1.63(1.19 \text { to } 2.21) \\
(1.65) \ddagger\end{array}$ & $\begin{array}{l}1.90(1.54 \text { to } 2.35) \\
(2.03) \ddagger\end{array}$ & $58 ;(58)^{\star} ;(54) \neq$ & $66 ;(70)^{\star} ;(63) \ddagger$ \\
\hline \multicolumn{9}{|l|}{ Men aged: } \\
\hline 45 years & 2 & \multirow[t]{3}{*}{315000} & \multirow[t]{3}{*}{4456} & 1.41 (1.03 to 1.94$)$ & 1.62 (1.26 to 2.09$)$ & 2.89 (2.31 to 3.62$)$ & 22 & 35 \\
\hline 55 years & 2 & & & 1.27 (1.02 to 1.57$)$ & 1.39 (1.09 to 1.75$)$ & 2.01 (1.46 to 2.76 ) & 25 & 43 \\
\hline 65 years & 2 & & & $1.18(0.90$ to 1.54$)$ & 1.21 (0.89 to 1.64$)$ & $1.44(0.96$ to 2.15$)$ & 15 & 30 \\
\hline \multicolumn{9}{|c|}{ Women aged: } \\
\hline 45 years & 1 & \multirow[t]{3}{*}{534000} & \multirow[t]{3}{*}{5512} & $1.40(0.93$ to 2.11$)$ & 1.60 (1.14 to 2.24$)$ & $2.64(2.20$ to 3.17$)$ & 24 & 37 \\
\hline 55 years & 1 & & & $1.25(0.95$ to 1.64$)$ & 1.41 (1.13 to 1.76$)$ & $2.22(1.97$ to 2.51$)$ & 20 & 34 \\
\hline 65 years & 1 & & & $1.12(0.85$ to 1.47$)$ & $1.25(1.00$ to 1.56$)$ & 1.87 (1.66 to 2.11$)$ & 14 & 29 \\
\hline \multicolumn{9}{|c|}{ Cardiovascular disease (coronary heart disease and stroke not reported separately) } \\
\hline Men & 7 & 111000 & 3480 & $\begin{array}{l}1.45(1.00 \text { to } 2.11) \\
(1.61) \ddagger\end{array}$ & $\begin{array}{l}1.59 \text { (1.11 to } 2.26) ; \\
(1.70) \neq\end{array}$ & $\begin{array}{l}2.19 \text { (1.56 to 3.09); } \\
(2.10) \ddagger\end{array}$ & 20; (38)*; (55)‡ & $34 ;(50)^{\star} ;(64) \neq$ \\
\hline Women & 1 & 153000 & 2768 & 1.65 (1.13 to 2.40$)$ & 1.74 (1.30 to 2.34$)$ & 2.16 (1.69 to 2.76$)$ & $56 ;(56)^{\star}$ & $64 ;(64)^{*}$ \\
\hline Combined & 4 & 1.00 million & 36525 & $\begin{array}{l}1.63(1.53 \text { to } 1.73) \\
(1.64) \ddagger\end{array}$ & $\begin{array}{l}1.71(1.63 \text { to } 1.80) \text {; } \\
(1.75) \ddagger\end{array}$ & $\begin{array}{l}2.27(1.96 \text { to } 2.62) \\
(2.25) \ddagger\end{array}$ & 50; (50); (51)‡ & $60 ;(56)^{\star} ;(60) \neq$ \\
\hline
\end{tabular}

day had $43 \%$ (14-55\%) the excess risk (relative risk 1.76) (fig 3; supplementary figure $C$. (Excluding one study that might have included former smokers in the reference group increased the relative risks for one and 20 cigarettes per day to 1.63 and 2.87.)

All of these estimates were similar to those obtained from the meta-regression (using a single model across studies) (table 1). Also, the relative risk estimates for one, five, and 20 cigarettes per day were mostly similar when produced by pooling these separately across studies (not within study analysis) to those from the meta-regressions (within study analysis).

There was a suggestion that the relative risks at low consumption might be higher for women than for men (1.57 $v 1.48$ for one cigarette per day; $1.76 v 1.58$ for five cigarettes per day), consistent with a higher risk of coronary heart disease in women reported by others. ${ }^{73}$ A comparison between sexes could also be examined directly within the same study cohort, where a higher relative risk was seen, without modelling: Hirayama et al (relative risk 1.61 for women versus 1.50 for men, for smoking one to four cigarettes per day), ${ }^{29}$ Nilsson et al (1.47 $v 1.24$, for smoking one to seven cigarettes per day), ${ }^{53}$ Prescott et al $(2.14 \mathrm{~V} 1.03$, for smoking three to five cigarettes per day), ${ }^{72}$ and Bjartveit et al $(2.94 \mathrm{~V}$ 2.74 , for smoking one to four cigarettes per day). ${ }^{17}$

Supplementary figure D shows the forest plots for the age and sex adjusted relative risks in five studies for which results were not reported separately by sex: consuming one or five cigarettes per day had 53\% or $61 \%$ of the excess risk, compared with 20 cigarettes per day (table 1). Supplementary figures E and F are the forest plots for coronary heart disease and smoking consumption in men and women separately for people aged 45, 55, and 65 years. The individual relative risks among men reflect the decreasing strength of association between coronary heart disease and smoking as people get older. The excess risk for smoking one cigarette per day expressed as a percentage of that for 20 cigarettes per day remained high throughout (fig 2): $35 \%, 33 \%$, and $20 \%$ for a man aged 45,55 , and 65 years, respectively; the corresponding figures for women were $11 \%, 15 \%$, and $36 \%$ (in which the older age group seems to have a larger estimate, but 


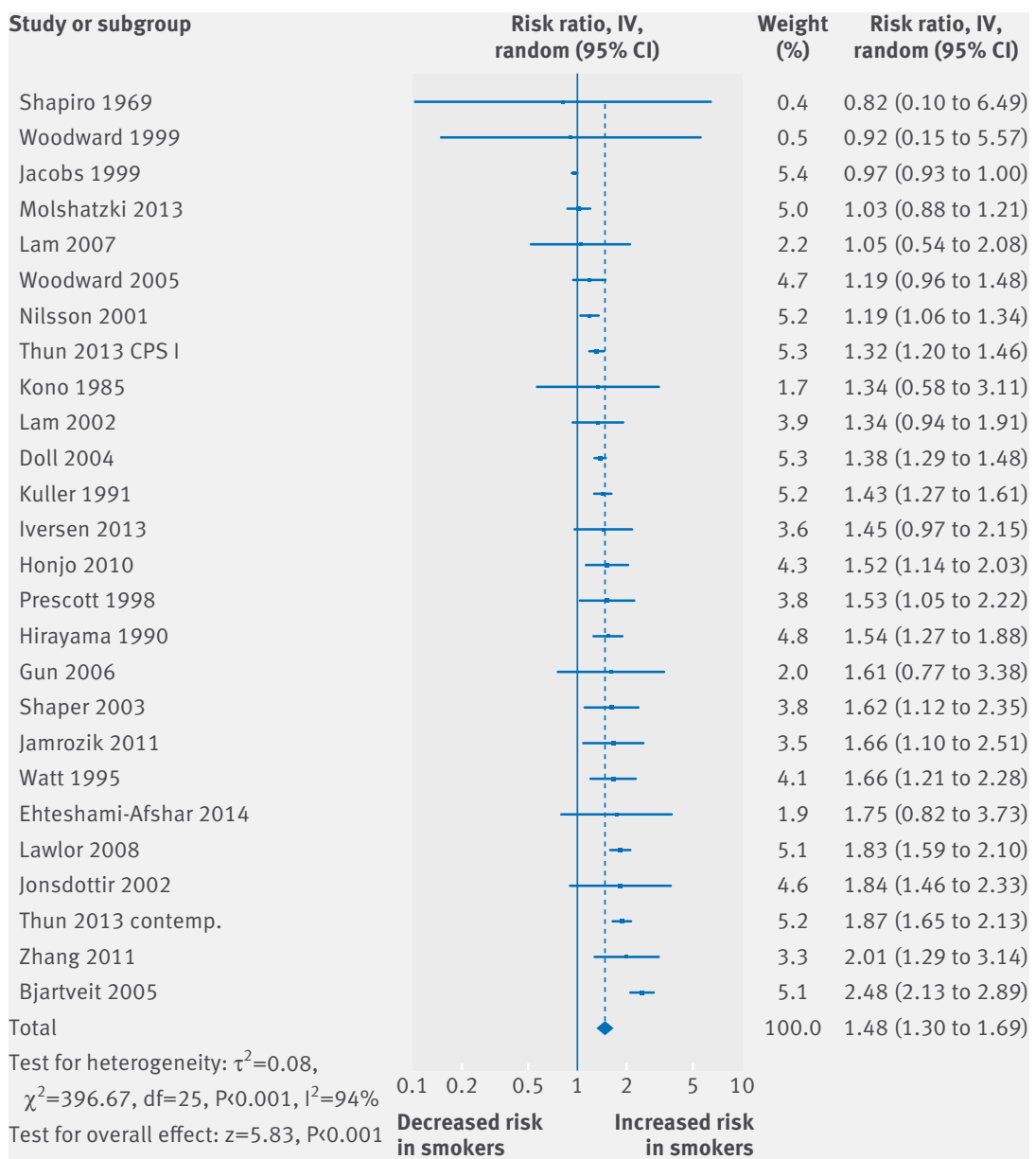

Fig 1 | Relative risk for coronary heart disease for men smoking one cigarette per day. IV=inverse variance. Studies are in reference numbers 16-70. Excluding five studies that used relative risks instead of hazard ratios increased pooled relative risk (to 1.53)

there were only three studies here). Table 1 shows the results for five cigarettes per day.

All estimates (men, women, and both together) are much higher than the expected $5 \%$ had a linear or loglinear relation existed between consumption and risk.

\section{Stroke}

Figure 4 and supplementary figures $\mathrm{G}$ and $\mathrm{H}$ show the relative risks for stroke. Among men who smoked one cigarette per day, the relative risk was 1.25 (1.13 to 1.38 ); for women, it was 1.31 (1.13 to 1.52$)$. The corresponding estimates for smoking 20 cigarettes per day were 1.64 (1.48 to 1.82 ) and 2.16 (1.69 to 2.75). These are again consistent with a slightly larger effect of smoking in women at the lowest smoking levels but more so at higher consumption, compared with men ( $1.44 v 1.30$ for five cigarettes per day; $2.16 v 1.64$ for 20 cigarettes per day), as seen elsewhere. ${ }^{73}$

From the within study analyses (fig 2), the distribution of excess relative risks again showed that most exceeded $25 \%$. Smoking one cigarette per day had an estimated $41 \%$ (interquartile range $-7-62 \%$ ) of the excess relative risk of men who smoked 20 cigarettes per day (from 17 studies), and the corresponding figure for five cigarettes per day was 52\% (9-70\%). These were similar to the findings in women (10 studies), in whom one cigarette per day had 34\% (3-51\%) of the excess risk of 20 cigarettes per day and five cigarettes per day had 44\% (16-60\%).

Supplementary figure I shows the forest plots for the age and sex adjusted relative risks. Supplementary figure J shows the forest plots for stroke and cigarette consumption in men according to age. The excess risk for smoking one cigarette per day expressed as a percentage of that for 20 cigarettes per day was $22 \%$, $25 \%$, and $15 \%$ for a man aged 45, 55, and 65 years (two studies); the corresponding figures for women were $24 \%, 20 \%$, and $14 \%$ (although these were based on only one study).

As with coronary heart disease, all estimates for stroke (men, women, and both together) were much higher than the $5 \%$ value expected with a linear or loglinear relation.

\section{All cardiovascular disease}

Supplementary figures $\mathrm{K}$ and $\mathrm{L}$ are forest plots for cardiovascular disease (coronary heart disease and stroke reported together), showing adjusted relative risks in men or women. Again, results were consistent with those seen for each disorder separately.

\section{Heterogeneity and bias}

The heterogeneity seen in some meta-analyses is largely due to statistically significant relative risk estimates that differ from each other, and several reasons for this may exist (for example, with or without adjustment for multiple confounders). In figure 1, 15 estimates for one cigarette per day were each statistically significant, ranging between 1.19 and 2.48. However, even the lowest relative risk of 1.19 is a significant increase in risk of coronary heart disease (representing $25 \%$ of the excess risk compared with its corresponding estimate for 20 cigarettes per day: relative risk=1.77).

We explored the possibility that some heavy smokers reduced to light smoking during the course of the study, which in turn might substantially reduce the relative risks in the high consumption categories, moving them closer to that for light smokers, when using baseline consumption to produce relative risks. This could overestimate the excess relative risk for one to five cigarettes per day when compared with that for 20 cigarettes per day. Such changes in smoking habits are expected to have largely occurred in the later years, so we examined only studies that had follow-up to 1995 , to see whether the relative risks were much higher than those based on all studies. This was not the case. The pooled relative risks for coronary heart disease associated with smoking 20 cigarettes per day were 1.8 (1.6 to 2.0) for men and 2.5 (2.0 to 3.1) for women, a modest reduction compared with 2.0 and 2.8 from all studies in table 1 . Also, we found no evidence of a negative trend between size of relative risk for smoking 20 cigarettes per day and last calendar year of follow-up (which might suggest many heavy smokers cutting down, and whether this increases over time): Spearman's correlations were positive: $0.30(\mathrm{P}=0.15)$ 


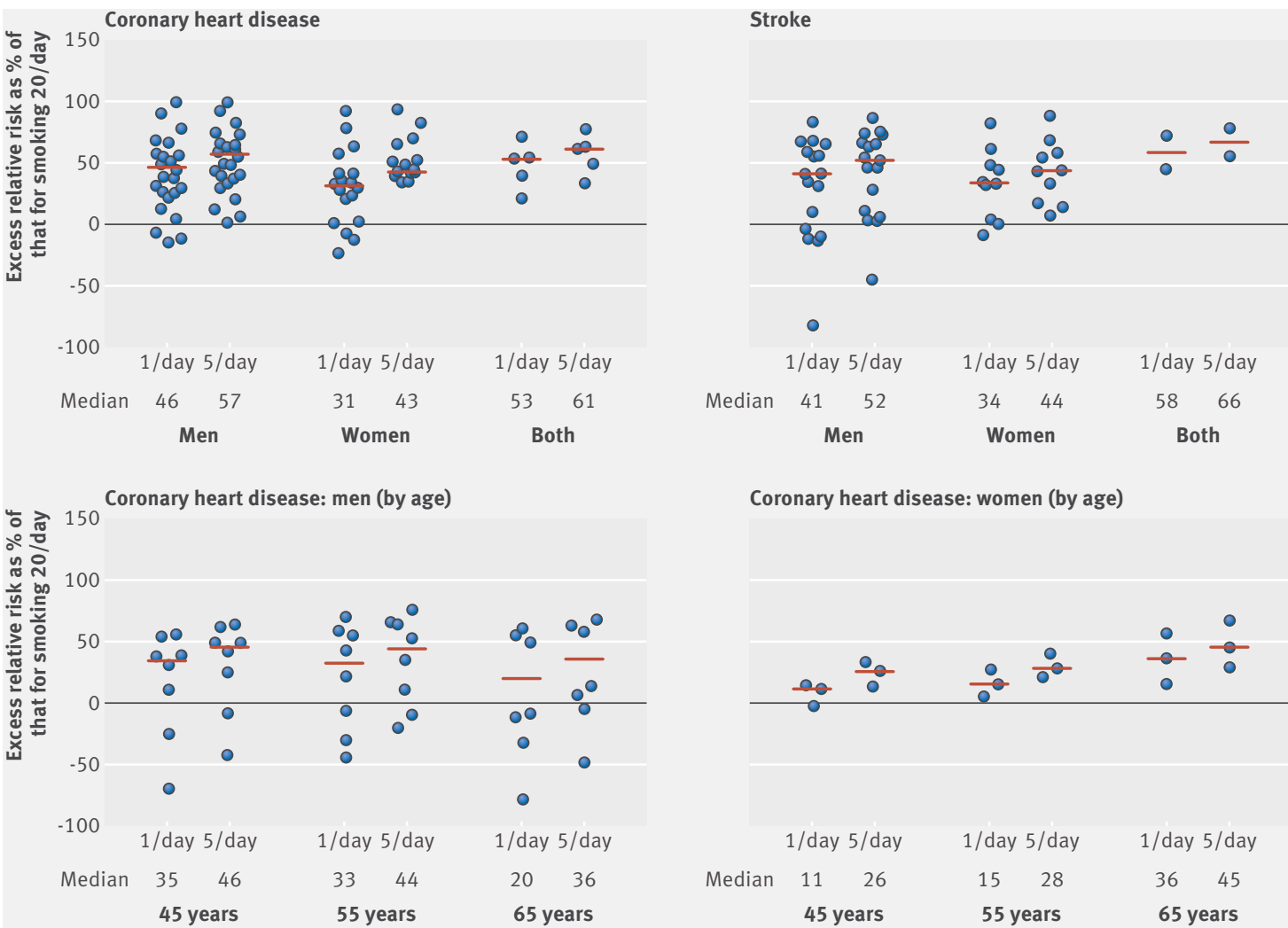

Fig 2 | Distribution of excess relative risk for smoking one or five cigarettes per day, each in relation to smoking 20 per day, using within study results (horizontal dashes show median). For example, in Lawlor et al (2008), ${ }^{48}$ estimated relative risk for coronary heart disease (CHD) was 1.83 or 2.63 for those smoking one or 20 per day, respectively (from regression analysis of this study). Proportion of excess relative risk associated with one cigarette per day is therefore $51 \%$ : $(1.83-1) /(2.63-1)$, which is plotted. (A negative value is when relative risk for one (or five) per day is $<1.0$.) For CHD in men, one study (Wen et al 2004) ${ }^{66}$ reported decreasing relative risks for increasing consumption for $\geq 65$ age group, which appears as excess relative risk percentage of $>100 \%$ (for completeness these are kept in, but do not affect median value)

for men and $0.33(\mathrm{P}=0.20)$ for women (coronary heart disease studies).

Three large studies (from different countries: Denmark, Norway, and South Korea) specifically examined the effect of reduced smoking on risk of cardiovascular disease. In one study (19423 adults), only $7.2 \%$ of "heavy" smokers (at least 15 cigarettes per day) reduced their consumption by at least $50 \%$ but continued to smoke when assessed five to 10 years after baseline (verified by carbon monoxide or cotinine concentrations). There was no clear risk reduction for coronary heart disease compared with continuing heavy smokers after 14 years' follow-up (adjusted relative risk 1.06), in contrast to a relative risk of 0.67 for quitters. ${ }^{74}$ However, a large reduction in risk of lung cancer was seen in the group who reduced consumption (relative risk 0.44). ${ }^{75}$ In the second study (51 210 adults), 4.2\% of heavy smokers (at least 15 cigarettes per day) reduced their consumption by at least $50 \%$ but continued to smoke when recorded three to 13 years after baseline. The adjusted relative risk for cardiovascular disease after 21 years' follow-up was 1.02 (compared with continuing heavy smokers), unlike the benefit seen in quitters (relative risk 0.46) or the positive effect on risk of lung cancer in those who reduced (relative risk 0.66). ${ }^{76}$ In the third study (475 734 adults), 5.2\% of heavy smokers (at least 20 cigarettes per day) reduced to less than 10 cigarettes per day two years later, with little risk reduction after nine years' follow-up (adjusted relative risk 0.85 for stroke and 0.92 for coronary heart disease, compared with continuing heavy smokers), in contrast to the beneficial effect in quitters (relative risk 0.70 for stroke and 0.43 for coronary heart disease) ${ }^{77}$ and the effect on lung cancer in those who reduced (relative risk 0.66) ${ }^{78}$ These studies indicate that a substantial bias is unlikely to be produced by heavy smokers cutting down, because only a small proportion did so, and that those who reduced consumption did not seem to have much benefit in terms of cardiovascular disease risk.

\section{Model reliability}

We checked the reliability of the regression models by comparing the estimated relative risks for smoking one, five, and 20 cigarettes per day with those seen in several individual studies that reported results specifically for low consumption (one to seven cigarettes per day). Our modelled estimates were close to those observed (supplementary table B). A high 


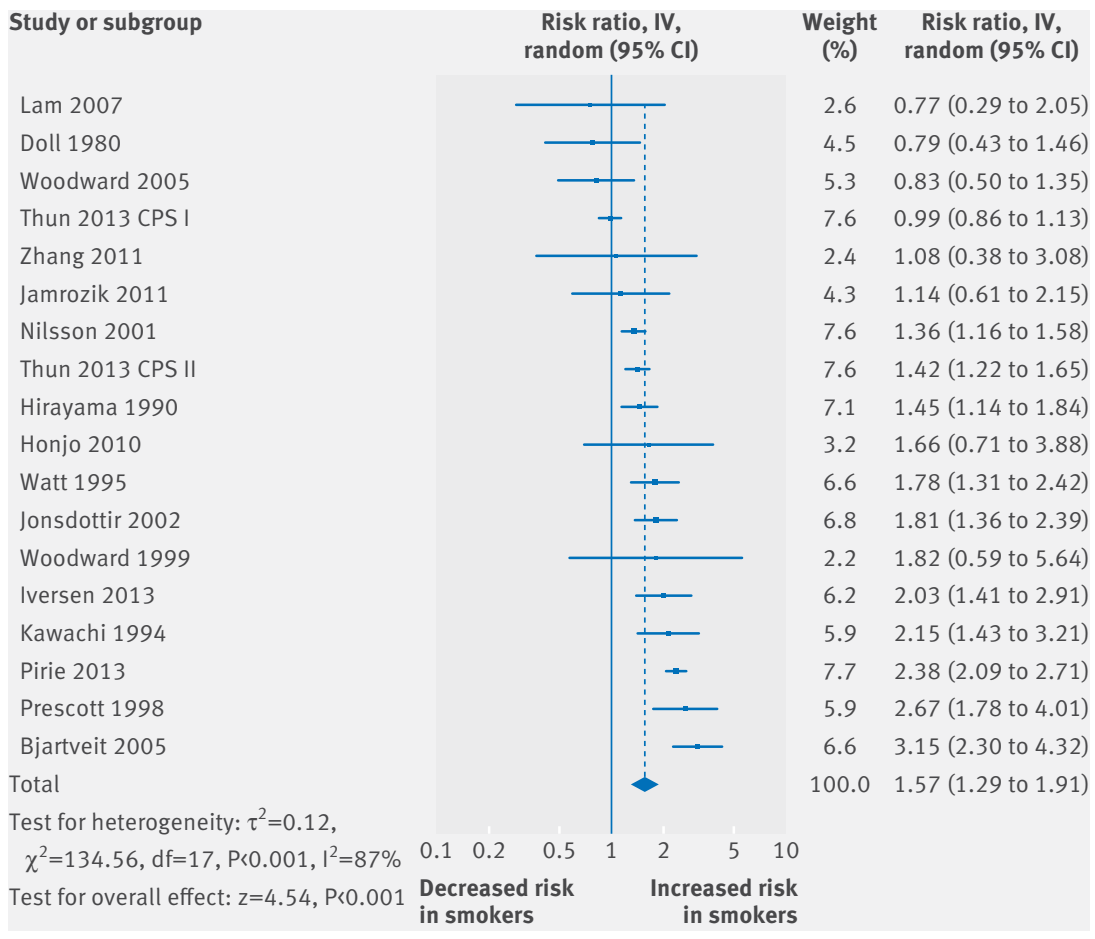

Fig 3 | Relative risk for coronary heart disease for women smoking one cigarette per day. IV=inverse variance. Studies are in reference numbers 16-70. Excluding two studies that used relative risks instead of hazard ratios slightly increased pooled relative risks (to 1.63). for multiple confounders: 1.36 and 1.89 for one and 20 cigarettes per day, and the excess relative risk for one cigarette per day is $36 \%$ (lower than the estimate when we used adjusted relative risks). Among women (nine studies), ${ }^{173236394755586770}$ the pooled adjusted relative risks were 2.19 and 3.95 for one and 20 cigarettes per day; and one cigarette per day represents $38 \%$ of the excess relative risk for 20 cigarettes per day. The pooled relative risks for the other nine studies that did not allow for multiple confounders were 1.26 and 2.11 for one and 20 cigarettes per day, and the excess relative risk for one cigarette per day was $25 \%$ (again, lower than the estimate when we used adjusted relative risks).

Among men, there were six studies of stroke, ${ }^{28} 40$ 42485160 and the pooled adjusted relative risks were 1.30 and 1.56 for smoking one and 20 cigarettes per day, with one cigarette per day representing $64 \%$ of the excess relative risk for 20 cigarettes per day. In the other 11 studies that did not allow for multiple confounders, the pooled relative risks were 1.20 and 1.68 for one and 20 cigarettes per day, and one cigarette per day had $38 \%$ of the excess relative risk for 20 cigarettes per day. Among women (five studies), ${ }^{28} 38$ 404755 the relative risks for stroke were 1.46 and 2.42 for one and 20 cigarettes per day, and one cigarette per day had $36 \%$ of the excess relative risk for 20 cigarettes per day. In the other five studies without multiple adjustment, the relative risks were 1.15 and 1.94 (15\% of the excess relative risk).

All of the studies that reported results for men and women combined had relative risks adjusted for multiple confounders. Estimates of excess relative risk associated with one cigarette per day were $47 \%$ (coronary heart disease), 54\% (stroke), and 51\% (cardiovascular disease), from the meta-regressions in table 1. As with previous analyses, the adjusted relative risks among women for smoking one cigarette per day were higher than for men $(2.19 \mathrm{~V}$ 1.74 for coronary heart disease and $1.46 \mathrm{~V} 1.30$ for stroke) (table 2).

\section{Confounding}

We explored the influence of confounding factors by doing meta-analyses according to whether studies made allowance for three or more factors (which in addition to age included cholesterol for studies of coronary heart disease and cholesterol or blood pressure for studies of stroke) (table 2). One study did not adjust for either cholesterol or blood pressure but made allowance for multiple other confounders, so we also included it with the "adjusted" group. ${ }^{55}$ Additional factors often included body mass index, education, history of diabetes, and physical activity (see supplementary table A).

Among men, 11 studies of coronary heart disease had multivariable adjusted relative risks, $1722323646-4858$ 606770 and the pooled relative risks were 1.74 and 2.27 for smoking one and 20 cigarettes per day (table 2). From the meta-regressions, one cigarette per day has $53 \%$ of the excess relative risk of 20 cigarettes per day. These adjusted relative risks were higher than those obtained from the 15 other studies that did not allow

\section{Study quality}

Study quality is difficult to assess, particularly when examining old studies, because "positive" design attributes were often not reported in publications. Our aim was not to examine a new association between a risk factor and a disorder but rather to use a feature of an already established causal relation, so the question of study quality is not so relevant. However, the variability in different observational study designs is the reason why we focused only on prospective cohort studies. Nevertheless, we examined study quality with the Newcastle-Ottawa assessment scale for cohort studies, ${ }^{79}$ using the largest set (that is, the 26 studies of coronary heart disease in men). Of these, we considered 15 to be "good quality," and the pooled relative risk for smoking one cigarette per day was 1.62 (1.45 to 1.82), higher than that based on all studies (relative risk 1.48); our interest was in whether it would be substantially lower. 


Study or subgroup
Men
Hirayama 1990
Kondo 2011
Nilsson 2001
Fuller 1983

Fig 4 | Relative risk for stroke for smoking one cigarette per day in men (top) and women (bottom). Studies are in reference numbers 16-70. IV=inverse variance. Excluding four studies in men and one study in women that used relative risks instead of hazard ratios slightly increased pooled relative risks to 1.28 for men and 1.34 for women

\section{Discussion}

We have shown that a large proportion of the risk of coronary heart disease and stroke comes from smoking only a few cigarettes. This has important consequences for smokers who believe that light smoking carries little or no harm. Our estimates for people who smoke one or five cigarettes per day represent light smoking, given that the daily habits of such smokers typically vary between one and five cigarettes per day. We have also indicated that the relative risk for smoking either one or five cigarettes per day seemed to be higher among women than men. Smoking one cigarette per day carries around 40$50 \%$ of the excess risk for developing coronary heart disease and stroke of smoking 20 cigarettes per day, and smoking five cigarettes per day has around 55$65 \%$ of the excess risk (particularly when we focused on studies that reported relative risks adjusted for multiple confounders).

The high relative risk associated with low smoking levels is seen clearly in individual cohort studies (supplementary table B). For example, in one study (42722 people), the relative risk for coronary heart disease among men was 2.74 (one to four cigarettes per day), representing $63 \%$ of the excess relative risk for smoking 20-24 cigarettes per day (relative risk 3.75). ${ }^{17}$ This contrasts with the effects observed for lung cancer in the same study, with relative risks of 2.79 versus $31.69,{ }^{17}$ representing $6 \%$ of the excess relative risk, consistent with a linear relation between cigarette consumption and risk-that is, $5 \%$ of the consumption associated with about $5 \%$ of the excess risk, which has also been shown in other large studies. ${ }^{1055} \mathrm{~A}$ recent study (290 215 US adults) showed that consistent light smoking throughout a lifetime also has a large excess risk for cardiovascular disease mortality: hazard ratio 2.78 for smoking less than one cigarette per day and 1.50 for one to 10 cigarettes per day, compared with 2.77 and 3.16 for smoking 21-30 and more than 30 cigarettes per day, respectively. ${ }^{80}$

We have also confirmed that low cigarette consumption is associated with a high risk of stroke. This evidence is further supported by studies of secondhand smoke in never smokers, ${ }^{81-84}$ in the same way as for coronary heart disease. ${ }^{12} 83$ In a meta-analysis of seven studies of never-smokers, ${ }^{82}$ the relative risks for developing stroke associated with second-hand smoke, compared with unexposed never smokers, were 1.35 (95\% confidence interval 1.22 to 1.50 ) in all participants, 1.40 (1.09 to 1.81) among men, and 1.43 (1.28 to 1.61) among women, consistent with our results for actively smoking one cigarette per day.

Potential confounding is worth considering. Different studies adjusted for different factors, but always for at least age and sex (when men and women were analysed together), which are two important confounders for cardiovascular disease. However, heavy smokers tend to have more adverse cardiovascular risk factors than light smokers (such as higher body mass index and central adiposity and poorer diet). ${ }^{85-87}$ Therefore, light smokers should have characteristics that are more protective against cardiovascular disease, compared with heavier smokers. Adjusting for these other risk factors should attenuate differences in cardiovascular disease risk between light and heavy smokers, not dilute them, such that when these factors are allowed for the estimates of excess risk for one or five cigarettes per day, in relation to 20 , should be even larger than when based on all studies together. This is what we found when focusing only on studies that had adjusted for multiple confounding factors (table 2).

The relative risks for coronary heart disease and stroke in our analyses are in line with that for all current smokers reported by Thun et al 2013 using several cohort studies, ${ }^{62}$ and they also suggest that the association between smoking and these disorders has got stronger over time. For coronary heart disease, an earlier estimate of relative risk was 1.78 among men 


\begin{tabular}{|c|c|c|c|c|c|c|c|}
\hline \multirow[b]{2}{*}{ Cohort and analysis* } & \multirow[b]{2}{*}{ No of studies } & \multicolumn{3}{|c|}{ From pooling results for 1 and 20 CPD separately across studies } & \multicolumn{3}{|c|}{ From meta-regressions (uses within study analyses) } \\
\hline & & $\mathrm{RR}(95 \% \mathrm{CI})$ for $1 \mathrm{CPD}$ & $\mathrm{RR}(95 \% \mathrm{CI})$ for $20 \mathrm{CPD}$ & Excess RR (\%)† & RR for 1 CPD & RR for 20 CPD & Excess RR (\%)† \\
\hline \multicolumn{8}{|c|}{ Coronary heart disease } \\
\hline \multicolumn{8}{|l|}{ Men: } \\
\hline Adjusted & 11 & $1.74(1.50$ to 2.03$)$ & 2.27 (1.90 to 2.72$)$ & 58 & 1.65 & 2.22 & $53(54)$ \\
\hline Unadjusted & 15 & $1.36(1.18$ to 1.56$)$ & 1.89 (1.71 to 2.08$)$ & 40 & 1.33 & 1.91 & $36(38)$ \\
\hline \multicolumn{8}{|l|}{ Women: } \\
\hline Adjusted & 9 & 2.19 (1.84 to 2.61$)$ & $3.95(3.34$ to 4.67$)$ & 40 & 2.12 & 3.98 & $38(34)$ \\
\hline Unadjusted & 9 & 1.26 (1.07 to 1.49$)$ & 2.11 (1.91 to 2.34$)$ & 23 & 1.28 & 2.12 & $25(23)$ \\
\hline \multicolumn{8}{|l|}{ Stroke } \\
\hline \multicolumn{8}{|l|}{ Men: } \\
\hline Adjusted & 6 & 1.30 (1.11 to 1.53$)$ & $1.56(1.31$ to 1.86$)$ & 54 & 1.35 & 1.55 & $64(62)$ \\
\hline Unadjusted & 11 & $1.20(1.07$ to 1.35$)$ & 1.68 (1.45 to 1.95$)$ & 29 & 1.26 & 1.68 & $38(34)$ \\
\hline \multicolumn{8}{|l|}{ Women: } \\
\hline Adjusted & 5 & $1.46(1.20$ to 1.78$)$ & $2.42(1.67$ to 3.52$)$ & 32 & 1.50 & 2.39 & $36(33)$ \\
\hline Unadjusted & 5 & 1.15 (0.98 to 1.35$)$ & 1.94 (1.44 to 2.61$)$ & 16 & 1.14 & 1.91 & $15(34)$ \\
\hline
\end{tabular}

compared with 2.50 in more recent cohort studies, with similar figures for women (2.0 previously and now 2.86). However, some of this effect could be due to decreasing exposure to second-hand smoke in the reference group (never smokers) after the introduction of smoke-free legislation. If the effect is becoming stronger, the relative risk for light smokers could now be even higher than we report, with a potentially greater percentage of excess risk in relation to heavier smokers. Although we had only summary data (hence limited ability to show trends reliably), we saw some suggestion of a positive trend between the size of the relative risk for smoking one cigarette per day and the last calendar year of follow-up for each study: Spearman's correlation $0.51(\mathrm{P}=0.008)$ for men and $0.21(\mathrm{P}=0.42)$ for women when we used studies of coronary heart disease, and $0.23(\mathrm{P}=0.39)$ and 0.56 $(\mathrm{P}=0.11)$ among men and women for studies of stroke.

Owing to the large effect of tobacco smoke at low doses, exposure to second-hand smoke in the reference group (never smokers) might lead to underestimation of the relative risk for one and 20 cigarettes per day and consequently dilute the percentage effect of one compared with 20 cigarettes per day. The extent of this depends on the degree of contamination (particularly for women who have never smoked, who might be more likely to be exposed to second-hand smoke from their husbands in earlier studies than men who never smoked) and the reliability of measuring exposure to second-hand smoke. Many of the studies started before smoke-free laws were implemented. Only one study adjusted for second-hand smoke, ${ }^{32}$ and the reported relative risks for coronary heart disease associated with one versus 20 cigarettes per day were 1.45 versus 1.82 in men and 2.03 versus 2.63 in women, in line with those from the meta-analyses.

\section{Strengths of study}

Strengths of our analyses include that we combined data from 55 cohort study reports (which together contained 141 separate cohort studies), many of which were large. For example, the studies of coronary heart disease in men were together based on approximately 3.07 million participants, including more than 75000 cases of coronary heart disease; for stroke, the total was approximately 3.53 million men, including at least 73000 cases. Similarly, for women, the combined studies contained around 2.56 million participants, including at least 36000 cases of coronary heart disease, with corresponding numbers of 3.78 million and 62000 cases in studies of stroke. The metaanalyses should therefore provide sufficiently reliable estimates of relative risks associated with low and high cigarette consumption. By using only prospective cohort studies, in which smoking consumption is recorded before development of cardiovascular disease, we avoid biases associated with retrospective designs, such as case-control studies. We report results separately for three disease groups (coronary heart disease, stroke, and cardiovascular disease), each according to sex and age. We also did three types of statistical analyses. Importantly, results showed consistency between men and women, between the disease groups, and between the different forms of analysis.

\section{Limitations of study}

Our analyses also had some limitations. Firstly, we did not have individual level data for study participants (many studies are old). A few datasets of cardiovascular disease and smoking are publicly available, but our aim was to be comprehensive and not restrict ourselves to having only a few studies. Furthermore, cigarette consumption is often recorded in categories (such as one to five and six to 10 cigarettes per day), not a specific number, so the ability to do regression modelling using whole numbers of cigarettes (rather than categories) is limited. Also, smokers are not expected to consume the same number of cigarettes each day, so using categories probably better reflects their intake. Having 
raw data would allow more sophisticated models between risk and consumption to be examined (with increased power for these analyses), compared with using a log-linear regression of summary data (based on only several smoking categories). However, our aim was to get sufficiently good approximate estimates of the excess risks in relation to the primary comparison: between the lowest and about 20 cigarettes per day group, rather than describe the whole dose-response range. As such, our estimates are supported by two sources of evidence (several individual studies and a potentially more sensitive dose-response model from a large study). The first source comprises the effects reported in individual studies (supplementary table B), showing a consistently high observed relative risk of coronary heart disease/stroke at the lowest cigarette consumption, relative to the highest consumption group, without using a fitted model, 1729333950535557 637172 which are in line with our modelled estimates. The second source comprises the results from one of the largest studies (Cancer Prevention Study II), ${ }^{10}$ in which the authors fitted a non-linear model between a measure of tobacco smoke (particular matter: $\mathrm{PM}_{2.5}$ ) and the relative risk for cardiovascular disease, using their raw data. The model was: relative risk $=1+\left(0.2685 \times \mathrm{PM}_{2.5} \operatorname{dose}^{0.2730}\right)$. An inhaled $\mathrm{PM}_{2.5}$ dose of about $12 \mathrm{mg}$ corresponds to about one cigarette per day, which produces a relative risk of 1.53 (both sexes combined), reassuringly in between our estimate of 1.48 for men and 1.57 for women (coronary heart disease) using our simpler log-linear model (and close to 1.63 for cardiovascular disease and both sexes combined). The relative risk estimate for 20 cigarettes per day from the more sophisticated model is 2.20 , so one cigarette per day represents $44 \%$ of the excess relative risk ((1.53-1)/(2.20-1)), close to our estimate of $50 \%$ (cardiovascular disease both sexes; table 1). Furthermore, the Cancer Prevention Study II showed that there was no low threshold associated with a safe level of smoking in relation to cardiovascular disease risk, for which even an inhaled $\mathrm{PM}_{2.5}$ dose of $1 \mathrm{mg}$ (one twelfth of a cigarette per day) has an expected relative risk of $1.25 .^{10}$

Secondly, methods are available for estimating doseresponse associations for meta-analyses that take into account that relative risk estimates across smoking categories are expected to be correlated within a study because they use the same reference group (never smokers in our case). One such method requires frequency counts in each exposure group and assumes that adjusted relative risks are similar to unadjusted ones. ${ }^{88}$ However, frequency data were not reported for many studies, and it is essential to use age adjusted relative risks because age is an important confounder for cardiovascular disease; and ideally other known confounders should also be accounted for. One main consequence of using methods such as this is that they produce wider $95 \%$ confidence intervals, which is unlikely to change our conclusions.

Thirdly, we used number of cigarettes per day, which is the most commonly reported measure, including in high profile studies. ${ }^{55}$ Although duration of smoking is also important when considering risk, it is highly correlated with age, which itself is a risk factor, so separating their effects can be difficult ${ }^{89}$; however, large studies tend to show a relation between duration and risk. ${ }^{89}$ Because light smoking seems to have dramatic effects on cardiovascular disease, shorter duration might also be associated with a higher than expected risk. This was confirmed in three cohort studies that reported duration, ${ }^{38} 5090$ and Pope et al 2011 concluded that the steep association with cigarettes per day did not materially change when duration was allowed for in the Cancer Prevention Study II study. ${ }^{10}$ In another study, ${ }^{50}$ the relative risk for less than 10 years' smoking duration was 1.73 , compared with 2.51 for $30-40$ years' duration, representing $48 \%$ of the excess relative risk (and these relative risks had been adjusted for number of cigarettes smoked per day). Similarly, the relative risk for smoking one to five cigarettes per day was 1.88 , representing $40 \%$ of the excess relative risk for smoking 15-20 cigarettes per day (3.20), and these relative risks had been adjusted for duration (years) of smoking. Although long duration has persistent cumulative effects, a large proportion of the risk seems to occur in the short term. ${ }^{91}$

Fourthly, some heavy smokers could misreport as light smokers at baseline (or vice versa, although few like this are expected), but if this represented a substantial proportion there would probably be nonlinear associations between consumption and the risk of other disorders (for example, lung cancer), which is generally not seen in large studies. ${ }^{10} 1755$ However, self reported smoking status has been shown to be acceptable, at least in older observational studies. ${ }^{92}$ Even if we assumed that misclassification was so extreme that it halved the excess risk for coronary heart disease for one cigarette per day (from table 1, 24\% for men where relative risk $=1.48$ and $29 \%$ for women where relative risk=1.57), these estimates would still be substantially higher than the $5 \%$ expected if assuming a linear relation with risk.

\section{Supporting biological mechanisms}

Substantial biological evidence shows that components of cigarette smoke lead to endothelial injury, cell dysfunction, atherosclerosis and acute thrombosis, and decreased ability of the blood to carry oxygen. ${ }^{84} 89$ Several such studies were summarised previously with regards to increased platelet aggregation and increased carotid arterial wall thickening at low cigarette consumption, and coronary heart disease and stroke may have common underlying pathways. ${ }^{12} 84$ Harmful effects at low doses are further supported by studies of second-hand smoke that show adverse actions on subclinical vascular disease and thickening of carotid artery walls. ${ }^{89}$ Barnoya and Glantz describe a wide range of potential mechanisms by using a comprehensive literature review to purport that platelet and endothelial function, arterial stiffness, atherosclerosis, oxidative stress, inflammation, heart 
rate variability, energy metabolism, and increased infarct size are all sensitive to second-hand smoke. ${ }^{93}$ They also noted that even brief exposure to secondhand smoke has notable adverse effects on these mechanisms, compared with that in active smokers. Three recent experimental studies focused on low consumption/exposure. ${ }^{94-96}$ In one study, 29 smokers each consumed a single cigarette, immediately after which they had a significant decrease in blood vessel output power and significant increase in blood vessel ageing level and remaining blood volume 25 minutes later, as markers of atherosclerosis. ${ }^{94}$ In another study, human coronary artery endothelial cells were exposed to the smoke equivalent to one cigarette, which led to activation of oxidant stress sensing transcription factor NFR2 and up-regulation of cytochrome p450, considered to have a role in the development of heart disease. ${ }^{95}$ These effects were not seen when heart cells were exposed to the vapour from one e-cigarette. ${ }^{95}$ A study exposed adult mice to low intensity tobacco smoke (two cigarettes) for one to two months and found adverse histopathological effects on brain cells. ${ }^{96}$

Indirect evidence for large harmful effects seen at low consumption also comes from studies reporting significantly reduced hospital admissions for cardiovascular disease shortly after the introduction of smoke-free legislation in various countries, ${ }^{97-101}$ including systematic reviews. ${ }^{83} 102103$ One such review, based on 45 studies, showed that the risk of hospital admission was reduced by $15 \%$ for all coronary events and $16 \%$ for cerebrovascular events. ${ }^{104}$ The authors reported that the benefit remained with longer follow-up after the legislation was implemented, and greater risk reductions were seen with more comprehensive laws.

\section{Occasional smokers and reduced smoking}

Limited data exist on the increase in risk among occasional or non-daily smokers. A previous study found a $50 \%$ increased risk of cardiovascular disease mortality among men in Finland who smoked occasionally. ${ }^{105}$ Of those who reported smoking daily or occasionally in the Smoking Toolkit Study in England, only $2 \%$ smoked less than one cigarette per day ("very light”), ${ }^{106}$ but just over $10 \%$ smoked on a non-daily basis. ${ }^{107}$ The non-daily smokers in the Smoking Toolkit Study smoked on average 5.2 cigarettes a day, ${ }^{107}$ so their risk is probably similar to that reported in our review.

In the results section, we outlined three large studies that reported little benefit on the risk of cardiovascular disease among heavy smokers who significantly reduced their consumption (unlike the large risk reduction for lung cancer), further supportive of a substantial effect of light smoking on cardiovascular disease. More evidence exists on the beliefs about health and reduced smoking (as opposed to quitting), in addition to the large US study mentioned in the introduction. ${ }^{9}$ One survey among 12-15 year old students showed that almost
$60 \%$ of regular smokers believed that occasional smoking carried little or no health risks, ${ }^{108}$ and in another study $60 \%$ of e-cigarette users said that the reason for using e-cigarettes was to reduce cigarette consumption in order to reduce health risks. ${ }^{109}$ Even in a recent survey of 1602 people in France in 2014-15 (51\% were former or current smokers), $34 \%$ thought that smoking up to 10 cigarettes per day carried no risk of lung cancer, and only half of respondents believed that there was no safe cigarette. ${ }^{110}$ Other surveys indicate that smokers perceive harm reduction associated with cigarettes marketed as "light" or "low tar,"111-114 even though the scientific evidence shows no benefit. Although cutting down has clear benefits, particularly for risk of cancer, the reduction in cardiovascular disease risk is not as large as smokers might expect.

\section{Policy implications and future research}

Individual research studies on the effects of light smoking have occasionally appeared in the media. Examples include "Even a cigarette a day is bad for your health" in the New York Times in December 2016 and the BBC's "Light smoking doubles sudden death risk in women" in December 2012; governmental reports have also referred to this question. ${ }^{89}$ However, our paper is the first to combine results across many studies covering both coronary heart disease and stroke, making it a valuable reference that can be used to strengthen public health campaigns (including those on smoking cessation services) and to provide a strong health incentive for smokers to quit (particularly women), rather than cut down. We also hope to raise more awareness of the subject among cardiovascular health professionals, primary care physicians, and smoking cessation specialists.

Heart disease and stroke are common disorders and causes of death. In the UK, about 73000 deaths due to coronary heart disease and 41000 due to stroke occur each year (compared with 36000 for lung cancer), ${ }^{115}$ and this is after the decline in mortality over time, mainly due to prevention and better treatments. However, the number of deaths is greatly over-shadowed by the number of events: more than 493000 inpatient hospital episodes for coronary heart disease and 236000 for stroke each year. ${ }^{115}$ This means that many more people are living with cardiovascular disease, with a major effect on their social and physical functioning, as well as time off work and use of local health services. The situation is similar in the US, with 370000 deaths from coronary heart disease and 140000 from stroke each year (compared with 155000 for lung cancer), but the number of first heart attacks is 525000 and that of first strokes is $610000 .^{116117}$ Fifteen to $20 \%$ of all cardiovascular disease events might be attributable to smoking, representing a substantial number of people that require care and treatment, but many events are avoidable. Thun et al, using recent US cohort study data (beginning 2000-10), indicated that given the increasing relative risks for coronary 
heart disease over time, about two thirds of the coronary heart disease deaths that occur in smokers could be attributable to their habit. ${ }^{62}$

The impact of smoking in places like China is of major interest. Although smoking prevalence in China has decreased in recent years, the absolute number of smokers is high, with an estimated 1 million deaths (all causes) due to tobacco in $2010 .{ }^{118}$ In a nationally representative survey in 2010 , only $17 \%$ of current smokers said that they intended to quit, indicating that if Chinese smokers follow similar patterns to those in Western countries, many active smokers could be more inclined to reduce consumption rather than quit completely. ${ }^{119}$ The relatively low overall smoking prevalence among all Chinese women $(<2 \%)$ might mask differences between those in rural and urban areas, as well as habits in younger women. In a 2008 survey of girls and women aged 14-24 years at high school or college, $4.2 \%$ of those in urban areas were current smokers, double the $1.9 \%$ seen in rural areas; and $38 \%$ of those surveyed in the urban locations did not believe that smoking increases the risk of cardiovascular disease (compared with 6\% when asked about lung cancer). ${ }^{120}$

Quitting smoking greatly reduces the risk of cardiovascular disease, with important benefits gained soon after stopping (quicker than for cancer). 525584 89121 Smokers can use nicotine containing products such as gum, patches, and electronic cigarettes. Although e-cigarettes have had much attention, they are considered by several experts to be significantly safer than cigarettes, ${ }^{122} 123$ and they are believed to be partly responsible for the decline in smoking prevalence in the UK, ${ }^{124}$ findings that are in contrast to the claim that e-cigarettes help to maintain smoking rates. Therefore, they are an important component of harm reduction that can help people to quit completely, ${ }^{4}$ ${ }^{84}$ which is necessary to significantly reduce the risk of cardiovascular disease. Although specific adverse effects of e-cigarettes on the cardiovascular system could be investigated further, ${ }^{125}{ }^{126}$ such effects, if they exist, are unlikely to be as harmful as the high risk of cardiovascular disease associated with light smoking that we show here.

\section{Conclusions}

Smokers who cut down the number of cigarettes they use can benefit from large reductions in the risk of cancer and some benefits on cardiovascular disease. However, smoking only one to five cigarettes per day is associated with a risk of coronary heart disease and stroke that is substantially higher than many health professionals or smokers recognise (as much as half the risk of smoking 20 per day). We show clearly that no safe level of smoking exists for cardiovascular disease at which light smokers can assume that continuing to smoke does not lead to harm. Smokers need to quit completely rather than cut down if they wish to avoid most of the risk associated with heart disease and stroke, two common and major disorders caused by smoking.
Contributors: AH developed the study concept. SB and DM did the literature search and data extraction. DM did the statistical analyses, with assistance from JKM and AH. All authors were involved in drafting and finalising the manuscript. $\mathrm{AH}$ and DM contributed equally to the project. $\mathrm{AH}$ is the guarantor.

Funding: This study was supported by a core grant from Cancer Research UK (C444/A15953).

Competing interests: All authors have completed the ICMJE uniform disclosure form at www.icmje.org/coi_disclosure.pdf (available on request from the corresponding author) and declare: no support from any organisation for the submitted work; no financial relationships with any organisations that might have an interest in the submitted work in the previous three years; no other relationships or activities that could appear to have influenced the submitted work.

Ethical approval: Not needed

Data sharing: No additional data available.

Transparency declaration: AH affirms that the manuscript is an honest, accurate, and transparent account of the study being reported; that no important aspects of the study have been omitted; and that any discrepancies from the study as planned (and, if relevant, registered) have been explained.

This is an Open Access article distributed in accordance with the terms of the Creative Commons Attribution (CC BY 4.0) license, which permits others to distribute, remix, adapt and build upon this work, for commercial use, provided the original work is properly cited. See: http://creativecommons.org/licenses/by/4.0/

1 Eriksen M, Mackay J, Schluger N, Islami F, Drope J. The tobacco atlas. 5th ed. American Cancer Society, 2015.

2 Giovino GA, Mirza SA, Samet JM, et al, GATS Collaborative Group. Tobacco use in 3 billion individuals from 16 countries: an analysis of nationally representative cross-sectional household surveys. Lancet 2012;380:668-79. doi:10.1016/S01406736(12)61085-X

$3 \mathrm{Ng}$ M, Freeman MK, Fleming TD, et al. Smoking prevalence and cigarette consumption in 187 countries, 1980-2012. JAMA 2014;311:183-92. doi:10.1001/jama.2013.284692

4 Royal College of Physicians. Nicotine without smoke: tobacco harm reduction. RCP, 2016.

5 NHS Digital. Health Survey for England. https://data.gov.uk/dataset/ health_survey_for_england.

6 Jamal A, Homa DM, O'Connor E, et al. Current cigarette smoking among adults - United States, 2005-2014. MMWR Morb Mortal Wkly Rep 2015;64:1233-40. doi:10.15585/mmwr. mm6444a2

7 Lindson-Hawley N, Hartmann-Boyce J, Fanshawe TR, Begh R, Farley A Lancaster T. Interventions to reduce harm from continued tobacco use. Cochrane Database Syst Rev 2016;10:CD005231.

8 Denlinger-Apte RL, Joel DL, Strasser AA, Donny EC. Low nicotine content descriptors reduce perceived health risks and positive cigarette ratings in participants using very low nicotine content cigarettes. Nicotine Tob Res 2017;19:1149-54.

9 Amrock SM, Weitzman M. Adolescents' perceptions of light and intermittent smoking in the United States. Pediatrics 2015;135: 246-54. doi:10.1542/peds.2014-2502

10 Pope CA3rd, Burnett RT, Turner MC, et al. Lung cancer and cardiovascular disease mortality associated with ambient air pollution and cigarette smoke: shape of the exposure-response relationships. Environ Health Perspect 2011;119:1616-21. doi:10.1289/ehp.1103639

11 Pechacek TF, Babb S. How acute and reversible are the cardiovascular risks of secondhand smoke? BMJ 2004;328:980-3. doi:10.1136/ bmj.328.7446.980

12 Law MR, Morris JK, Wald NJ. Environmental tobacco smoke exposure and ischaemic heart disease: an evaluation of the evidence. BMJ 1997;315:973-80. doi:10.1136/ bmj.315.7114.973

13 Stroup DF, Berlin JA, Morton SC, et al. Meta-analysis of observational studies in epidemiology: a proposal for reporting. Meta-analysis Of Observational Studies in Epidemiology (MOOSE) group. JAMA 2000;283:2008-12. doi:10.1001/jama.283.15.2008

14 Law MR, Morris JK, Watt HC, Wald NJ. The dose-response relationship between cigarette consumption, biochemical markers and risk of lung cancer. Br J Cancer 1997;75:1690-3. doi:10.1038/ bjc.1997.287

15 National Cancer Institute (NCl). Monograph 8: Changes in cigaretterelated disease risks and their implications for prevention and control . Division of Cancer Control and Population Science, $\mathrm{NCl}$, 1997

16 Abbott RD, Yin Y, Reed DM, Yano K. Risk of stroke in male cigarette smokers. N Engl J Med 1986;315:717-20. doi:10.1056/ NEJM198609183151201 
17 Bjartveit K, Tverdal A. Health consequences of smoking 1-4 cigarettes per day. Tob Control 2005;14:315-20. doi:10.1136/ tc. 2005.011932

18 Burns DM, Shanks TG, Choi W, Thun MJ, Heath CW Jr, Garfinkel L. The American Cancer Society Prevention Study I: 12-year follow up of 1 million men and women. In: Changes in cigarette-related disease risks and their implications for prevention and control, Chapter 3. Smoking and tobacco control monograph, number 8 , publication 97-4213, 1997

\{ label needed for ref[@id='ref19'] \} Garfinkel L. Selection, follow-up, and analysis in the American Cancer Society prospective studies. Natl Cancer Inst Monogr 1985;67:49-52.

19 Bush TL, Comstock GW. Smoking and cardiovascular mortality in women. Am J Epidemiol 1983;118:480-8. doi:10.1093/ oxfordjournals.aje.a113653

20 Doll R, Gray R, Hafner B, Peto R. Mortality in relation to smoking: 22 years' observations on female British doctors. Br Med J 1980;280:967-71. doi:10.1136/bmj.280.6219.967

21 Doll R, Peto R, Boreham J, Sutherland I. Mortality in relation to smoking: 50 years' observations on male British doctors. BMJ 2004;328:1519. doi:10.1136/bmj.38142.554479.AE

22 Ehteshami-Afshar S, Momenan A, Hajshekholeslami F, Azizi F, Hadaegh $F$. The impact of smoking status on 9.3 years incidence of cardiovascular and all-cause mortality among Iranian men. Ann Hum Biol 2014:41:249-54. doi:10.3109/03014460.2013.853834

23 Freund KM, Belanger AJ, D’Agostino RB, Kannel WB. The health risks of smoking. The Framingham Study: 34 years of follow-up. Ann Epidemiol 1993;3:417-24. doi:10.1016/1047-2797(93)90070-K

24 Fuller JH, Shipley MJ, Rose G, Jarrett RJ, Keen H. Mortality from coronary heart disease and stroke in relation to degree of glycaemia: the Whitehall study. Br Med I (Clin Res Ed) 1983;287:867-70. doi:10.1136/bmi.287.6396.867

25 Gellert C, Schöttker B, Müller H, Holleczek B, Brenner H. Impact of smoking and quitting on cardiovascular outcomes and risk advancement periods among older adults. Eur Epidemiol 2013;28:649-58. doi:10.1007/s10654-013-9776-0

26 Gun RT, Pratt N, Ryan P, Gordon I, Roder D. Tobacco and alcoholrelated mortality in men: estimates from the Australian cohort of petroleum industry workers. Aust N Z J Public Health 2006;30: 318-24. doi:10.1111/j.1467-842X.2006.tb00842.x

27 Hart CL, Hole DJ, Smith GD. Comparison of risk factors for stroke incidence and stroke mortality in 20 years of follow-up in men and women in the Renfrew/Paisley Study in Scotland. Stroke 2000;31:1893-6. doi:10.1161/01.STR.31.8.1893

28 Hippisley-Cox J, Coupland C, Brindle P. Derivation and validation of QStroke score for predicting risk of ischaemic stroke in primary care and comparison with other risk scores: a prospective open cohort study. BMJ 2013;346:f2573. doi:10.1136/bmj.f2573

29 Hirayama T. Life-style and mortality: a large-scale census-based cohort study in Japan. Karger, 1990

30 Honjo K, Iso H, Tsugane S, et al. The effects of smoking and smoking cessation on mortality from cardiovascular disease among Japanese: pooled analysis of three large-scale cohort studies in Japan. Tob Control 2010;19:50-7. doi:10.1136/tc.2009.029751

31 Huxley RR, Yatsuya H, Lutsey PL, Woodward M, Alonso A, Folsom AR. Impact of age at smoking initiation, dosage, and time since quitting on cardiovascular disease in african americans and whites: the atherosclerosis risk in communities study. Am J Epidemiol 2012;175:816-26. doi:10.1093/aje/kwr391

32 Iversen B, Jacobsen BK, Løchen ML. Active and passive smoking and the risk of myocardial infarction in 24,968 men and women during 11 year of follow-up: the Troms $\varnothing$ Study. Eur Epidemiol 2013;28:659-67. doi:10.1007/s10654-013-9785-z

33 Jacobs DRJr, Adachi H, Mulder I, et al. Cigarette smoking and mortality risk: twenty-five-year follow-up of the Seven Countries Study. Arch Intern Med 1999;159:733-40. doi:10.1001/archinte.159.7.733

34 Jamrozik K, McLaughlin D, McCaul K, et al. Women who smoke like men die like men who smoke: findings from two Australian cohort studies. Tob Control 2011;20:258-65. doi:10.1136/ tc. 2010.039172

35 Ji J, Pan E, Li J, et al. Classical risk factors of cardiovascular disease among Chinese male steel workers: a prospective cohort study for 20 years. BMC Public Health 2011;11:497. doi:10.1186/1471 2458-11-497

36 Jónsdóttir LS, Sigfússon N, Gudnason V, Sigvaldason H, Thorgeirsson G. Do lipids, blood pressure, diabetes, and smoking confer equal risk of myocardial infarction in women as in men? The Reykjavik Study. J Cardiovasc Risk 2002;9:67-76. doi:10.1177/174182670200900201

37 Kahn HA. The Dorn study of smoking and mortality among U.S. veterans: report on eight and one-half years of observation. Nat Cancer Inst Monogr 1966;19:1-125.

38 Kawachi I, Colditz GA, Stampfer MJ, et al. Smoking cessation and decreased risk of stroke in women. JAMA 1993;269:232-6. doi:10.1001/jama.1993.03500020066033
39 Kawachi I, Colditz GA, Stampfer MJ, et al. Smoking cessation and time course of decreased risks of coronary heart disease in middleaged women. Arch Intern Med 1994;154:169-75. doi:10.1001/ archinte.1994.00420020075009

40 Kelly TN, Gu D, Chen J, et al. Cigarette smoking and risk of stroke in the chinese adult population. Stroke 2008:39:1688-93. doi:10.1161/STROKEAHA.107.505305

41 Khang YH, Lynch JW, Jung-Choi K, Cho HJ. Explaining age-specific inequalities in mortality from all causes, cardiovascular disease and ischaemic heart disease among South Korean male public servants: relative and absolute perspectives. Heart 2008;94:75-82. doi:10.1136/hrt.2007.117747

42 Kondo T, Osugi S, Shimokata K, et al. Smoking and smoking cessation in relation to all-cause mortality and cardiovascular events in 25,464 healthy male Japanese workers. Circ J 2011;75:2885-92. doi:10.1253/circj.CJ-11-0416

43 Kono S, Ikeda M, Tokudome S, Nishizumi M, Kuratsune M. Smoking and mortalities from cancer, coronary heart disease and stroke in male Japanese physicians. / Cancer Res Clin Oncol 1985;110:161-4. doi:10.1007/BF00402732

44 Kuller LH, Ockene JK, Meilahn E, Wentworth DN, Svendsen KH, Neaton JDMRFIT Research Group. Cigarette smoking and mortality. Prev Med 1991;20:638-54. doi:10.1016/0091-7435(91)90060-H

45 LaCroix AZ, Lang J, Scherr P, et al. Smoking and mortality among older men and women in three communities. N Engl/ Med 1991;324:1619-25. doi:10.1056/NEJM199106063242303

46 Lam TH, He Y, Shi QL, et al. Smoking, quitting, and mortality in a Chinese cohort of retired men. Ann Epidemiol 2002;12:316-20. doi:10.1016/S1047-2797(01)00258-7

47 Lam TH, Li ZB, Ho SY, et al. Smoking, quitting and mortality in an elderly cohort of 56,000 Hong Kong Chinese. Tob Control 2007:16:182-9. doi:10.1136/tc.2006.019505

48 Lawlor DA, Song YM, Sung J, Ebrahim S, Smith GD. The association of smoking and cardiovascular disease in a population with low cholesterol levels: a study of 648,346 men from the Korean national health system prospective cohort study. Stroke 2008;39:760-7. doi:10.1161/STROKEAHA.107.494823

49 Liaw KM, Chen Cl. Mortality attributable to cigarette smoking in Taiwan: a 12-year follow-up study. Tob Control 1998;7:141-8. doi:10.1136/tc.7.2.141

50 Merry AH, Boer JM, Schouten LJ, et al. Smoking, alcohol consumption, physical activity, and family history and the risks of acute myocardial infarction and unstable angina pectoris: a prospective cohort study. BMC Cardiovasc Disord 2011;11:13. doi:10.1186/1471-226111-13

51 Molshatzki N, Goldbourt U, Tanne D. Perceived hardships at midlife: prediction of long-term stroke mortality. Int J Cardiol 2013;168:2278-81. doi:10.1016/j.ijcard.2013.01.200

52 Mons U, Müezzinler A, Gellert C, et al, CHANCES Consortium. Impact of smoking and smoking cessation on cardiovascular events and mortality among older adults: meta-analysis of individual participant data from prospective cohort studies of the CHANCES consortium. BMJ 2015;350:h1551. doi:10.1136/bmj.h1551

53 Nilsson S, Carstensen JM, Pershagen G. Mortality among male and female smokers in Sweden: a 33 year follow up. J Epidemiol Community Health 2001;55:825-30. doi:10.1136/jech.55.11.825

54 Pham TM, Fujino Y, Ide R, et al. Mortality attributable to cigarette smoking in a cohort study in Japan. Eur J Epidemiol 2007;22: 599-605. doi:10.1007/s10654-007-9161-y

55 Pirie K, Peto R, Reeves GK, Green J, Beral VMillion Women Study Collaborators. The 21st century hazards of smoking and benefits of stopping: a prospective study of one million women in the UK. Lancet 2013;381:133-41. doi:10.1016/S01406736(12)61720-6

56 The Pooling Project Research Group. Relationship of blood pressure, serum cholesterol, smoking habit, relative weight and ECG abnormalities to incidence of major coronary events: final report of the pooling project. The pooling project research group. J Chronic Dis 1978;31:201-306. doi:10.1016/0021-9681(78)90073-5

57 Pope CA3rd, Burnett RT, Krewski D, et al. Cardiovascular mortality and exposure to airborne fine particulate matter and cigarette smoke: shape of the exposure-response relationship. Circulation 2009;120:941-8. doi:10.1161/ CIRCULATIONAHA.109.857888

58 Prescott E, Hippe M, Schnohr P, Hein HO, Vestbo J. Smoking and risk of myocardial infarction in women and men: longitudinal population study. BMJ 1998;316:1043-7. doi:10.1136/bmj.316.7137.1043

59 Ragland DR, Brand RJ. Coronary heart disease mortality in the Western Collaborative Group Study. Follow-up experience of 22 years. Am J Epidemiol 1988;127:462-75. doi:10.1093/oxfordjournals.aje. a114823

60 Shaper AG, Wannamethee SG, Walker M. Pipe and cigar smoking and major cardiovascular events, cancer incidence and all-cause mortality in middle-aged British men. Int J Epidemiol 2003;32:802-8. doi:10.1093/ije/dyg206 
61 Shapiro S, Weinblatt E, Frank CW, Sager RV. Incidence of coronary heart disease in a population insured for medical care (HIP): myocardial infarction, angina pectoris, and possible myocardial infarction. Am J Public Health Nations Health 1969;59(Suppl 6): 1-101. doi:10.2105/AJPH.59.Suppl_6.1

62 Thun MJ, Carter BD, Feskanich D, et al. 50-year trends in smokingrelated mortality in the United States. N Engl / Med 2013;368: 351-64. doi:10.1056/NEJMsa1211127

63 Tverdal A, Bjartveit K. Health consequences of pipe versus cigarette smoking. Tob Control 2011;20:123-30. doi:10.1136/ tc. 2010.036780

64 Watt GC, Hart CL, Hole DJ, Smith GD, Gillis CR, Hawthorne VM. Risk factors for cardiorespiratory and all cause mortality in men and women in urban Scotland: 15 year follow up. Scott Med / 1995;40:108-12. doi:10.1177/003693309504000403

65 Weir JM, Dunn JEJr. Smoking and mortality: a prospective study. Cancer 1970;25:105-12. doi:10.1002/10970142(197001)25:1<105::AID-CNCR2820250115>3.0.CO;2-Z

66 Wen CP, Tsai SP, Chen CJ, Cheng TY. The mortality risks of smokers in Taiwan: Part I: cause-specific mortality. Prev Med 2004;39:528-35. doi:10.1016/j.ypmed.2004.02.010

67 Woodward M, Moohan M, Tunstall-Pedoe H. Self-reported smoking, cigarette yields and inhalation biochemistry related to the incidence of coronary heart disease: results from the Scottish Heart Health Study. J Epidemiol Biostat 1999;4:285-95

68 Woodward M, Lam TH, Barzi F, et al, Asia Pacific Cohort Studies Collaboration. Smoking, quitting, and the risk of cardiovascular disease among women and men in the Asia-Pacific region. Int J Epidemiol 2005;34:1036-45. doi:10.1093/ije/dyi104

69 Xu WH, Zhang XL, Gao YT, et al. Joint effect of cigarette smoking and alcohol consumption on mortality. Prev Med 2007;45:313-9. doi:10.1016/i.ypmed.2007.05.015

70 Zhang QL, Baumert J, Ladwig KH, Wichmann HE, Meisinger C, Döring A. Association of daily tar and nicotine intake with incident myocardial infarction: results from the population-based MONICA/KORA Augsburg Cohort Study 1984-2002. BMC Public Health 2011;11:273. doi:10.1186/1471-2458-11-273

71 Rosengren A, Wilhelmsen L, Wedel H. Coronary heart disease, cancer and mortality in male middle-aged light smokers. J Intern Med 1992;231:357-62. doi:10.1111/j.1365-2796.1992.tb00944.x

72 Prescott E, Scharling H, Osler M, Schnohr P. Importance of light smoking and inhalation habits on risk of myocardial infarction and all cause mortality. A 22 year follow up of 12149 men and women in The Copenhagen City Heart Study. J Epidemiol Community Health 2002;56:702-6. doi:10.1136/jech.56.9.702

73 Huxley RR, Woodward M. Cigarette smoking as a risk factor for coronary heart disease in women compared with men: a systematic review and meta-analysis of prospective cohort studies. Lancet 2011;378:1297-305. doi:10.1016/S01406736(11)60781-2

74 Godtfredsen NS, Osler M, Vestbo J, Andersen I, Prescott E. Smoking reduction, smoking cessation, and incidence of fatal and non-fatal myocardial infarction in Denmark 1976-1998: a pooled cohort study. J Epidemiol Community Health 2003;57:412-6. doi:10.1136/ jech.57.6.412

75 Godtfredsen NS, Prescott E, Osler M. Effect of smoking reduction on lung cancer risk. JAMA 2005;294:1505-10. doi:10.1001/ jama.294.12.1505

76 Tverdal A, Bjartveit K. Health consequences of reduced daily cigarette consumption. Tob Control 2006;15:472-80. doi:10.1136/ tc. 2006.016246

77 Song YM, Cho HJ. Risk of stroke and myocardial infarction after reduction or cessation of cigarette smoking: a cohort study in korean men. Stroke 2008;39:2432-8. doi:10.1161/ STROKEAHA.107.512632

78 Song YM, Sung J, Cho HJ. Reduction and cessation of cigarette smoking and risk of cancer: a cohort study of Korean men. / Clin Oncol 2008;26:5101-6. doi:10.1200/JC0.2008.17.0498

79 Wells GA, Shea B, O'Connell D, et al. The Newcastle-Ottawa scale (NOS) for assessing the quality of nonrandomised studies in metaanalyses. 2009. https://www.ncbi.nlm.nih.gov/books/NBK99082/ bin/appb-fm4.pdf.

80 Inoue-Choi M, Liao LM, Reyes-Guzman C, Hartge P, Caporaso N, Freedman ND. Association of Long-term, Low-Intensity Smoking With All-Cause and Cause-Specific Mortality in the National Institutes of Health-AARP Diet and Health Study. JAMA Intern Med 2017;177: 87-95. doi:10.1001/jamainternmed.2016.7511

81 Royal College of Physicians. Going smoke-free: the medical case for clean air in the home, at work and in public places. A report on passive smoking by the Tobacco Advisory Group of the RCP. RCP, 2005.

82 Fischer F, Kraemer A. Meta-analysis of the association between second-hand smoke exposure and ischaemic heart diseases, COPD and stroke. BMC Public Health 2015;15:1202. doi:10.1186/ s12889-015-2489-4
83 U.S. Department of Health and Human Services. The health consequences of involuntary exposure to tobacco smoke: a report of the Surgeon General . Department of Health and Human Services, Centers for Disease Control and Prevention, Coordinating Center for Health Promotion, National Center for Chronic Disease Prevention and Health Promotion, Office on Smoking and Health, 2006.

84 U.S. Department of Health and Human Services. The health consequences of smoking: 50 years of progress. A report of the Surgeon General . Department of Health and Human Services, Centers for Disease Control and Prevention, Coordinating Center for Health Promotion, National Center for Chronic Disease Prevention and Health Promotion, Office on Smoking and Health, 2014.

85 Iredale JM, Clare PJ, Courtney RJ, et al. Associations between behavioural risk factors and smoking, heavy smoking and future smoking among an Australian population-based sample. Prev Med 2016;83:70-6. doi:10.1016/j.ypmed.2015.11.020

86 Alkerwi A, Baydarlioglu B, Sauvageot N, et al. Smoking status is inversely associated with overall diet quality: Findings from the ORISCAV-LUX study. Clin Nutr 2017;36:1275-82. doi:10.1016/j. clnu.2016.08.013

87 Chiolero A, Faeh D, Paccaud F, Cornuz J. Consequences of smoking for body weight, body fat distribution, and insulin resistance. Am J Clin Nutr 2008;87:801-9.

88 Greenland S, Longnecker MP. Methods for trend estimation from summarized dose-response data, with applications to meta-analysis Am J Epidemiol 1992;135:1301-9. doi:10.1093/oxfordjournals.aje. a116237

89 U.S. Department of Health and Human Services. How tobacco smoke causes disease. The biology and behavioral basis for smoking attributable disease. A report of the Surgeon General . Department of Health and Human Services, Centers for Disease Control and Prevention, Coordinating Center for Health Promotion, National Center for Chronic Disease Prevention and Health Promotion, Office on Smoking and Health, 2010.

90 Jee SH, Suh I, Kim IS, Appel LI. Smoking and atherosclerotic cardiovascular disease in men with low levels of serum cholesterol: the Korea Medical Insurance Corporation Study. JAMA 1999;282:2149-55. doi:10.1001/jama.282.22.2149

91 Pope CA, Brook RD, Burnett RT, Dockery DW. How is cardiovascular disease mortality risk affected by duration and intensity of fine particulate matter exposure? An integration of the epidemiologic evidence. Air Qual Atmos Health 2011;4:5-14doi:10.1007/s11869010-0082-7.

92 Patrick DL, Cheadle A, Thompson DC, Diehr P, Koepsell T, Kinne S. The validity of self-reported smoking: a review and meta-analysis. Am Public Health 1994;84:1086-93. doi:10.2105/AJPH.84.7.1086

93 Barnoya J, Glantz SA. Cardiovascular effects of secondhand smoke: nearly as large as smoking. Circulation 2005;111:2684-98. doi:10.1161/CIRCULATIONAHA.104.492215

94 MiYang J, HyeonCheol J, Lee K, Yim J. The acute effect of smoking a single cigarette on vascular status, SpO2, and stress level. Med Sci Monit 2014:20:601-7. doi:10.12659/MSM 890367

95 Teasdale JE, Newby AC, Timpson NJ, Munafò MR, White SJ. Cigarette smoke but not electronic cigarette aerosol activates a stress response in human coronary artery endothelial cells in culture. Drug Alcohol Depend 2016;163:256-60. doi:10.1016/j.drugalcdep.2016.04.020

96 Csabai D, Csekő K, Szaiff L, et al. Low intensity, long term exposure to tobacco smoke inhibits hippocampal neurogenesis in adult mice. Behav Brain Res 2016;302:44-52. doi:10.1016/j.bbr.2016.01.022

97 Sargent RP, Shepard RM, Glantz SA. Reduced incidence of admissions for myocardial infarction associated with public smoking ban: before and after study. BMJ 2004;328:977-80. doi:10.1136/ bmj.38055.715683.55

98 Sims M, Maxwell R, Bauld L, Gilmore A. Short term impact of smoke-free legislation in England: retrospective analysis of hospital admissions for myocardial infarction. BMJ 2010;340:C2161. doi:10.1136/bmj.c2161

99 Barr CD, Diez DM, Wang Y, Dominici F, Samet IM. Comprehensive smoking bans and acute myocardial infarction among Medicare enrollees in 387 US counties: 1999-2008. Am Epidemiol 2012;176:642-8. doi:10.1093/aje/kws267

100 Cronin EM, Kearney PM, Kearney PP, Sullivan P, Perry IJCoronary Heart Attack Ireland Registry (CHAIR) Working Group. Impact of a national smoking ban on hospital admission for acute coronary syndromes: a longitudinal study. Clin Cardiol 2012;35:205-9. doi:10.1002/clc.21014

101 Liu A, Guzman Castillo M, Capewell S, Lucy J, O’Flaherty M. Reduction in myocardial infarction admissions in Liverpool after the smoking ban: potential socioeconomic implications for policymaking. BMJ Open 2013;3:e003307. doi:10.1136/bmjopen-2013-003307

102 Meyers DG, Neuberger JS, He J. Cardiovascular effect of bans on smoking in public places: a systematic review and meta-analysis. I Am Coll Cardiol 2009;54:1249-55. doi:10.1016/j.jacc.2009.07.022

103 Mackay DF, Irfan MO, Haw S, Pell JP. Meta-analysis of the effect of comprehensive smoke-free legislation on acute coronary events. Heart 2010;96:1525-30. doi:10.1136/hrt.2010.199026 
104 Tan CE, Glantz SA. Association between smoke-free legislation and hospitalizations for cardiac, cerebrovascular, and respiratory diseases: a meta-analysis. Circulation 2012;126:2177-83. doi:10.1161/CIRCULATIONAHA.112.121301

105 Luoto R, Uutela A, Puska P. Occasional smoking increases total and cardiovascular mortality among men. Nicotine Tob Res 2000:2 133-9. doi:10.1080/713688127

106 Kotz D, Fidler J, West R. Very low rate and light smokers: smoking patterns and cessation-related behaviour in England, 200611. Addiction 2012;107:995-1002. doi:10.1111/j.13600443.2011.03739.x

107 Herbec A, Brown J, West R.Non-daily smoking in England - addressing common misconceptions. Smoking In Britain 2014;1(5)

108 Hamilton G, Cross D, Resnicow K. Occasional cigarette smokers: cue for harm reduction smoking education. Addict Res 2000;8:419-37. doi:10.3109/16066350009005588.

109 Rutten LJ, Blake KD, Agunwamba AA, et al. Use of E-Cigarettes Among Current Smokers: Associations Among Reasons for Use, Quit Intentions, and Current Tobacco Use. Nicotine Tob Res 2015;17:1228-34. doi:10.1093/ntr/ntv003

110 Greiller L, Couraud S, Touboul C, et al. Perception of lung cancer (LC) risk: Impact of smoking status and nicotine dependence. Ann Oncol 2015;26:i57doi:10.1093/annonc/ mdv128.01.

111 Fish LJ, Pollak KI, Scheuermann TS, Cox LS, Mathur C, Ahluwalia JS. Comparison of native light daily smokers and light daily smokers who were former heavy smokers. Nicotine Tob Res 2015;17:546-51. doi:10.1093/ntr/ntu169

112 Kropp RY, Halpern-Felsher BL. Adolescents' beliefs about the risks involved in smoking "light" cigarettes. Pediatrics 2004;114: e445-51. doi:10.1542/peds.2004-0893

113 Yong HH, Borland R, Cummings KM, et al. US Smokers' Beliefs, Experiences and Perceptions of Different Cigarette Variants Before and After the FSPTCA Ban on Misleading Descriptors Such as "Light," “Mild," or “Low". Nicotine Tob Res 2016;18:2115-23. doi:10.1093/ ntr/ntw107

114 Agaku IT, Omaduvie UT, Filippidis FT, Vardavas Cl. Cigarette design and marketing features are associated with increased smoking susceptibility and perception of reduced harm among smokers in 27 EU countries. Tob Control 2015;24(e4):e233-40. doi:10.1136/ tobaccocontrol-2014-051922

115 Bhatnagar P, Wickramasinghe K, Williams J, Rayner M, Townsend N. The epidemiology of cardiovascular disease in the UK 2014 Heart 2015;101:1182-9. doi:10.1136/heartjnl-2015-307516
116 Centers for Disease Control and Prevention. Heart disease facts. 2017. https://www.cdc.gov/heartdisease/facts.htm.

117 Centers for Disease Control and Prevention. Stroke facts. 2017. https://www.cdc.gov/stroke/facts.htm.

118 Chen Z, Peto R, Zhou M, et al, China Kadoorie Biobank (CKB) collaborative group. Contrasting male and female trends in tobacco-attributed mortality in China: evidence from successive nationwide prospective cohort studies. Lancet 2015;386:1447-56. doi:10.1016/S0140-6736(15)00340-2

119 Liu S, Zhang M, Yang L, et al. Prevalence and patterns of tobacco smoking among Chinese adult men and women: findings of the 2010 national smoking survey. J Epidemiol Community Health 2017;71:154-61. doi:10.1136/jech-2016-207805

120 Ho MG, Ma S, Chai W, Xia W, Yang G, Novotny TE. Smoking among rural and urban young women in China. Tob Control 2010;19:13-8. doi:10.1136/tc.2009.030981

121 Tang JL, Cook DG, Shaper AG. Giving up smoking: How rapidly does the excess risk of ischaemic heart disease disappear? Journal of Smoking-Related Diseases 1992;3:203-15.

122 Britton J, Edwards R, eds. Harm reduction in nicotine addiction: helping people who can't quit. A report by the Tobacco Advisory Group of the Royal College of Physicians. Royal College of Physicians, 2007.

123 McNeill A, Brose LS, Calder R, Hitchman SC. E-cigarettes: an evidence update: A report commissioned by Public Health England. Public Health England, 2015.

124 Beard E, West R, Michie S, Brown J. Association between electronic cigarette use and changes in quit attempts, success of quit attempts, use of smoking cessation pharmacotherapy, and use of stop smoking services in England: time series analysis of population trends. BMJ 2016;354:i4645. doi:10.1136/bmj.i4645

125 Carnevale R, Sciarretta S, Violi F, et al. Acute impact of tobacco versus electronic cigarette smoking on oxidative stress and vascular function. Chest 2016;150:606-12. doi:10.1016/j. chest.2016.04.012

126 Bhatnagar A, Whitsel LP, Ribisl KM, et al, American Heart Association Advocacy Coordinating Committee, Council on Cardiovascular and Stroke Nursing, Council on Clinical Cardiology, and Council on Quality of Care and Outcomes Research. Electronic cigarettes: a policy statement from the American Heart Association. Circulation 2014;130:1418-36. doi:10.1161/ CIR.0000000000000107

Supplementary: figures and tables 